\title{
Influence of Sintering Atmosphere on Abnormal Grain Growth Behaviour in Potassium Sodium Niobate Ceramics Sintered at Low Temperature
}

\author{
John G. Fisher ${ }^{* * *}$, Si-Young Choi ${ }^{* * *}$, and Suk-Joong L. Kang ${ }^{*, \dagger}$ \\ *Department of Materials Science and Engineering, Korea Advanced Institute of Science and Technology, Daejon 305-701, Korea \\ ${ }^{* *}$ School of Materials Science and Engineering, Chonnam National University, Gwangju 500-757, Korea \\ *** Korea Institute of Materials Science, Changwon 642-831, Korea
}

(Received September 24, 2011; Revised September 29, 2011; Accepted September 30, 2011)

\begin{abstract}
The present study aims to identify the effect of sintering atmosphere $\left[\mathrm{O}_{2}, 75 \mathrm{~N}_{2}-25 \mathrm{H}_{2}(\mathrm{~mol} \%)\right.$ and $\left.\mathrm{H}_{2}\right]$ on microstructural evolution at the relatively low sintering temperature of $1040^{\circ} \mathrm{C}$. Samples sintered in $\mathrm{O}_{2}$ showed a bimodal microstructure consisting of fine matrix grains and large abnormal grains. Sintering in $75 \mathrm{~N}_{2}-25 \mathrm{H}_{2}$ (mol \%) and $\mathrm{H}_{2}$ caused the extent of abnormal grain growth to increase. These changes in grain growth behaviour are explained by the effect of the change in step free energy with sintering atmosphere on the critical driving force necessary for rapid grain growth. The results show the possibility of fabricating $\left(\mathrm{K}_{0.5} \mathrm{Na}_{0.5}\right) \mathrm{NbO}_{3}$ at low temperature with various microstructures via proper control of sintering atmosphere.
\end{abstract}

Key words : Lead-free piezoelectric, Grain growth, Grain boundaries, Sintering atmosphere, Niobates

\section{Introduction}

I $\mathrm{n}$ recent years, a great deal of effort has gone into finding lead-free replacements for $\mathrm{Pb}(\mathrm{Zr}, \mathrm{Ti}) \mathrm{O}_{3}$ piezoceramics. One promising family of ceramics is based on solid solutions in the $\mathrm{KNbO}_{3}-\mathrm{NaNbO}_{3}$ pseudo-binary system. ${ }^{1)}$ Ceramics of the composition $\left(\mathrm{K}_{0.5} \mathrm{Na}_{0.5}\right) \mathrm{NbO}_{3}$ have moderate piezoelectric properties $\left(\mathrm{d}_{33}=70-90 \mathrm{pC} / \mathrm{N}, \mathrm{k}_{\mathrm{p}}=0.36-0.39\right.$, $\left.\mathrm{k}_{\mathrm{t}}=0.4\right)^{2,3)}$ that can be improved by addition of compounds which form solid solutions with $\left(\mathrm{K}_{0.5} \mathrm{Na}_{0.5}\right) \mathrm{NbO}_{3}^{4,5)}$ or by producing grain-oriented ceramics. ${ }^{6,7}$

It has been noted in the literature that $\left(\mathrm{K}_{0.5} \mathrm{Na}_{0.5}\right) \mathrm{NbO}_{3}$ displays abnormal grain growth, with the microstructure consisting of large abnormal grains surrounded by fine matrix grains. ${ }^{8-11)}$ Abnormal grain growth is generally undesirable as it can inhibit densification ${ }^{12,13)}$ and may also lead to unfavourable dielectric and mechanical properties. ${ }^{10,11)}$ Although many studies have been carried out on improving the sinterability of $\left(\mathrm{K}_{0.5} \mathrm{Na}_{0.5}\right) \mathrm{NbO}_{3}$, few detailed studies exist concerning microstructural development. Recent experiments have shown that sintering $\left(\mathrm{K}_{0.5} \mathrm{Na}_{0.5}\right) \mathrm{NbO}_{3}$ in reducing atmospheres can reduce abnormal grain growth. ${ }^{14,15)}$ Samples sintered in $\mathrm{O}_{2}$ or $\mathrm{N}_{2}$ had very coarse microstructures with grains up to $50 \mu \mathrm{m}$ in diameter but in samples sintered in $75 \mathrm{~N}_{2}-25 \mathrm{H}_{2}(\mathrm{~mol} \%)$ or $\mathrm{H}_{2}$, the amount of abnormal grain growth could be reduced or entirely suppressed. This change in microstructure was caused by an increase in the concen-

'Corresponding author : Suk-Joong L. Kang

E-mail : sjkang@kaist.ac.kr

Tel : +82-42-350-4113 Fax : +82-42-350-3310 tration of oxygen vacancies in the samples sintered in reducing atmospheres. ${ }^{15,16)}$ This reduced the critical driving force necessary for grain growth, causing a transition from abnormal to pseudo-normal grain growth. ${ }^{17)}$ In the previous work, samples were sintered at $1100^{\circ} \mathrm{C}$. Changes in sintering temperature can also have an effect on abnormal grain growth behaviour as the critical driving force for grain growth is also dependant on temperature. ${ }^{17}$ In the present work the effect of sintering at a lower temperature in various atmospheres will be studied.

\section{Experimental}

The mixed oxide method was used to prepare powders of $\left(\mathrm{K}_{0.5} \mathrm{Na}_{0.5}\right) \mathrm{NbO}_{3} . \mathrm{K}_{2} \mathrm{CO}_{3}$ (99.5\%, Junsei), $\mathrm{Na}_{2} \mathrm{CO}_{3}(99.8 \%$, Acros) and $\mathrm{Nb}_{2} \mathrm{O}_{5}(99.9 \%$, Grand Chemical \& Material) were mixed in appropriate amounts and ball milled in ethanol for $24 \mathrm{~h}$, using $\mathrm{ZrO}_{2}$ milling media and polypropylene jars. In order to remove any adsorbed water, the $\mathrm{K}_{2} \mathrm{CO}_{3}$ and $\mathrm{Na}_{2} \mathrm{CO}_{3}$ powders were dried at $250^{\circ} \mathrm{C}$ overnight and the $\mathrm{Nb}_{2} \mathrm{O}_{5}$ powder was dried at $80^{\circ} \mathrm{C}$ overnight before weighing. After ball milling, the ethanol was evaporated using a hot plate and magnetic stirrer. The resulting powder was ground with an agate mortar and pestle and passed through a $180 \mu \mathrm{m}$ sieve. The powder was loaded into an alumina crucible with a lid and calcined at $750^{\circ} \mathrm{C}$ for $5 \mathrm{~h}$. The calcined powder was examined by X-ray diffraction (Rigaku D/MAX-IIIC, Tokyo, Japan) and found to be single phase perovskite. The calcined powder was ball milled and sieved as before to break up any agglomerates. The particle size distribution after ball-milling was measured using a laser particle size analyser (Photal Otsuka Electronics ELS-Z2, Hirakata, Japan). The particle size distribution of 
the starting powder was asymmetric, with a peak at $205 \mathrm{~nm}$ and a tail out to $310 \mathrm{~nm}$. The mean and standard deviation of the particle radius were $217 \mathrm{~nm}$ and $25 \mathrm{~nm}$ respectively.

Samples were made by compressing by hand $0.5 \mathrm{~g}$ of powder in a steel die $10 \mathrm{~mm}$ in diameter. Samples were then removed from the die and cold isostatically pressed at $200 \mathrm{MPa}$.

Samples were sintered in a closed-end alumina tube in a vertical tube furnace in atmospheres of flowing $\mathrm{O}_{2}, 75 \mathrm{~N}_{2}-25$ $\mathrm{H}_{2}(\mathrm{~mol} \%)$ or $\mathrm{H}_{2}$ (flow rate $\approx 150 \mathrm{~cm}^{3} \cdot \mathrm{min}^{-1}$ ) at $1040^{\circ} \mathrm{C}$ for 0.5-10 h. The heating and cooling rates were $5^{\circ} \mathrm{C} . \mathrm{min}^{-1}$. Samples were placed in an alumina crucible without a lid. The crucible was lined with square spacers made from sintered $\left(\mathrm{K}_{0.5} \mathrm{Na}_{0.5}\right) \mathrm{NbO}_{3}$ to prevent the samples from touching the crucible walls. To prevent the samples from sintering to each other, a small amount of $\left(\mathrm{K}_{0.5} \mathrm{Na}_{0.5}\right) \mathrm{NbO}_{3}$ powder was placed between samples.

The density of the sintered samples was measured by Archimedes' method in distilled water. For each sintering experiment, three samples were measured three times each, and the mean and standard deviation taken. For microscopy, samples were sectioned and polished to a $0.25 \mu \mathrm{m}$ finish. Scanning electron microscopy (SEM) was carried out using a Phillips XL30 SEM (Phillips, Eindhoven, Netherlands). To observe the microstructure, polished samples were thermally etched at temperatures between $990-1035^{\circ} \mathrm{C}$ for $60 \mathrm{~min}$ in air. All samples were Pt coated. Grain size distributions were measured using the same method as in our previous work. ${ }^{14)}$ Microscopy was also carried out on polished but unetched samples.

For Transmission Electron Microscopy (TEM), samples were prepared by the normal methods of dimpling and ion beam milling. Conventional TEM micrographs were taken using a JEOL 3010 and a JEOL JEM-2100F TEM (JEOL, Tokyo, Japan). Electron Energy Loss Spectroscopy (EELS) was carried out in the JEOL JEM-2100F across grain boundaries in the samples sintered for $2 \mathrm{~h}$ in $\mathrm{O}_{2}$ and $\mathrm{H}_{2}$. The $\mathrm{O} / \mathrm{K}$ ratios were measured at $\sim 30 \mathrm{~nm}$ intervals crossing the grain boundary. The probe size was $\sim 3 \mathrm{~nm}$.

$\mathrm{X}$-ray diffraction (XRD) of samples sintered for $10 \mathrm{~h}$ was carried out on a Rigaku D/MAX-2500 diffractometer (Rigaku, Tokyo, Japan). Scans were carried out using a $2 \theta$ scan range of $20-60^{\circ}$, a scan speed of $1^{\circ} \cdot \mathrm{min}^{-1}$ and a step size of $0.01^{\circ}$. The unit cell parameters and volume of the samples were determined by Rietveld refinement.

\section{Results}

The density of the samples is shown in Fig. 1. The theoret-

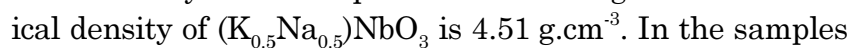
sintered in $\mathrm{O}_{2}$, the density increases with sintering time up to $2 \mathrm{~h}$ and then the rate of densification decreases. The density of the samples sintered in $75 \mathrm{~N}_{2}-25 \mathrm{H}_{2}$ (mol \%) is noticeably higher than that of the $\mathrm{O}_{2}$-sintered samples, even after only $0.5 \mathrm{~h}$. Density increases with sintering time up to $2 \mathrm{~h}$, and then decreases. Sample density increases further as the sintering atmosphere changes from $75 \mathrm{~N}_{2}-25 \mathrm{H}_{2}$ (mol \%) to $\mathrm{H}_{2}$.

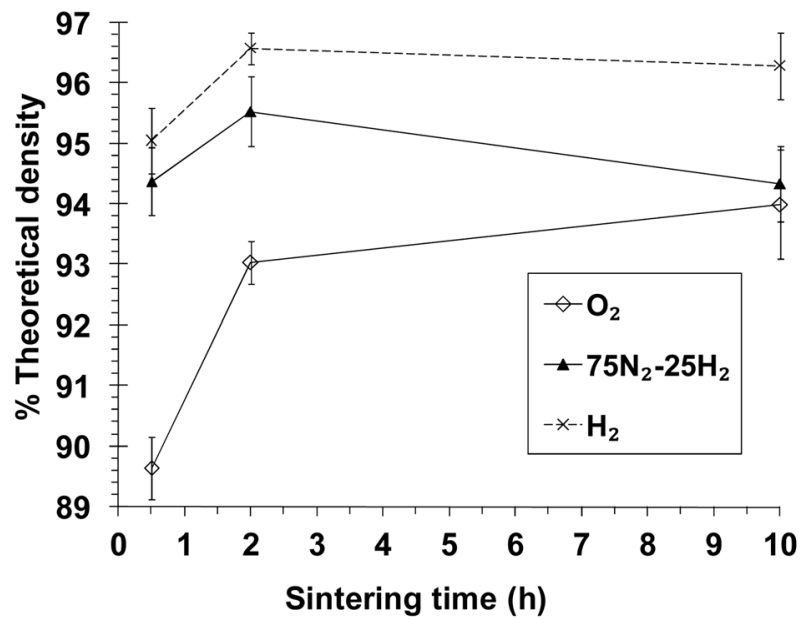

Fig. 1. Density of $\left(\mathrm{K}_{0.5} \mathrm{Na}_{0.5}\right) \mathrm{NbO}_{3}$ samples sintered in different atmospheres at $1040^{\circ} \mathrm{C}$ for different times.

For the samples sintered in $\mathrm{H}_{2}$, density increases with sintering time up to $2 \mathrm{~h}$, and then levels off.

SEM secondary electron images of samples sintered for $2 \mathrm{~h}$ are shown in Fig. 2 (a)-(d). The sample sintered in $\mathrm{O}_{2}$ has a bimodal microstructure consisting of matrix grains between $1-3 \mu \mathrm{m}$ in diameter and abnormal grains up to $70 \mu \mathrm{m}$ in diameter [Fig. 2 (a)]. Both the matrix and the abnormal grains are cuboid in shape with faceted edges. The abnormal grains contain many trapped pores. There is also intergranular porosity between the matrix grains. The sample sintered in $75 \mathrm{~N}_{2}-25 \mathrm{H}_{2}$ (mol\%) has an extremely coarse microstructure, with grains up to $140 \mu \mathrm{m}$ in diameter [Fig. 2 (b)]. Large pores are visible at the grain boundaries and triple junctions, and many pores are trapped within the grains. Some of the grains lose their cubic shape and appear to have curved grain boundaries. However, at higher magnification the boundaries show micro-faceting, indicating that they are still faceted [Fig. 2 (c), marked with arrows]. The sample sintered in $\mathrm{H}_{2}$ has a similar microstructure, but with smaller grains (maximum grain diameter of $\sim 120 \mu \mathrm{m}$ ) [Fig. 2 (d)]. The number of pores trapped within the grains also appears to decrease. Fig. 2 (e) and (f) show backscattered electron images of polished samples sintered in $\mathrm{O}_{2}$ and 75 $\mathrm{N}_{2}-25 \mathrm{H}_{2}$ (mol \%) for $2 \mathrm{~h}$. No secondary phases are visible. No secondary phases were also visible on backscattered electron images of a polished sample sintered in $\mathrm{H}_{2}$.

Grain size distributions of the samples are shown in Fig. 3. In the samples sintered in $\mathrm{O}_{2}$, abnormal grain growth has already taken place after sintering for $0.5 \mathrm{~h}$ [Fig. 3 (a)]. The grain size distribution is bimodal; the majority of grains are micron-sized, but abnormal grains up to $50 \mu \mathrm{m}$ in diameter are also present. As sintering proceeds, the grain size distribution becomes broader as the number and size of abnormal grains increase. The samples sintered in $75 \mathrm{~N}_{2}-25 \mathrm{H}_{2}$ (mol\%) have a much broader grain size distribution than the samples sintered in $\mathrm{O}_{2}$. Abnormal grain growth is essentially complete after only $0.5 \mathrm{~h}$ of sintering, with grains up to $60 \mu \mathrm{m}$ in 

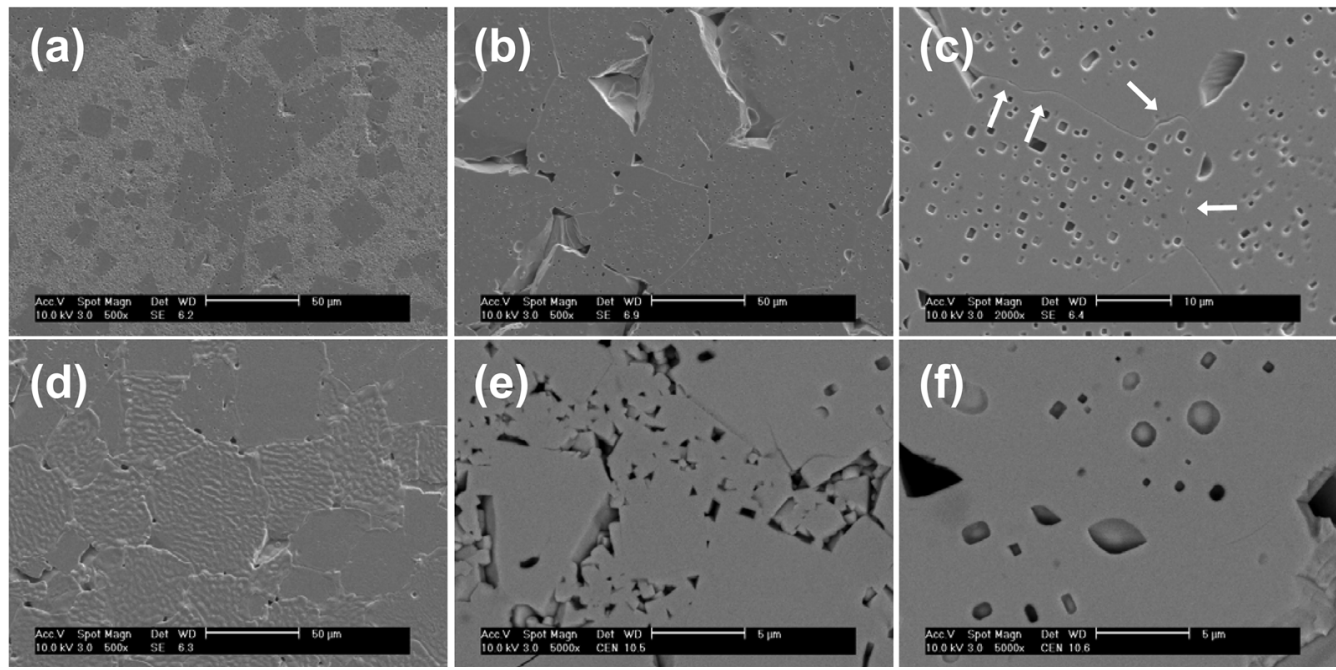

Fig. 2. (a)-(d): $\mathrm{SEM}$ secondary electron micrographs of $\left(\mathrm{K}_{0.5} \mathrm{Na}_{0.5}\right) \mathrm{NbO}_{3}$ ceramics sintered at $1040^{\circ} \mathrm{C}$ for $2 \mathrm{~h}$ in: (a) $\mathrm{O}_{2}$, (b) and (c) $75 \mathrm{~N}_{2}-25 \mathrm{H}_{2}$ (mol\%), (d) $\mathrm{H}_{2}$. White arrows in (c) show microfaceting.

(e)-(f): SEM backscattered electron micrographs of $\left(\mathrm{K}_{0.5} \mathrm{Na}_{0.5}\right) \mathrm{NbO}_{3}$ ceramics sintered at $1040^{\circ} \mathrm{C}$ for $2 \mathrm{~h}$ in: (e) $\mathrm{O}_{2}$ and (f) $75 \mathrm{~N}_{2}-25 \mathrm{H}_{2}(\mathrm{~mol} \%)$.
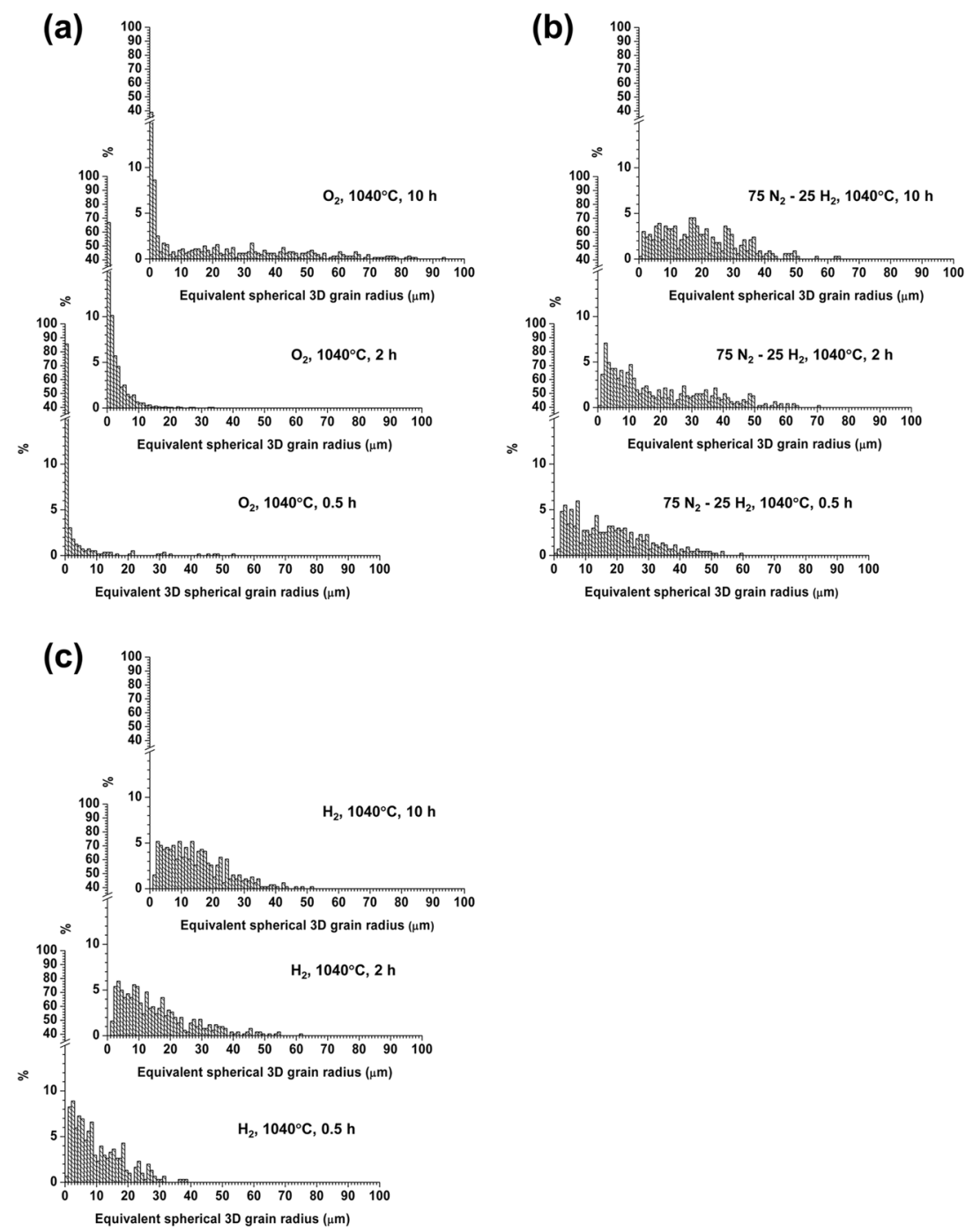

Fig. 3. Grain size distributions of $\left(\mathrm{K}_{0.5} \mathrm{Na}_{0.5}\right) \mathrm{NbO}_{3}$ ceramics sintered at $1040^{\circ} \mathrm{C}$ in: (a) $\mathrm{O}_{2}$, (b) $75 \mathrm{~N}_{2}-25 \mathrm{H}_{2}$ (mol\%), and (c) $\mathrm{H}_{2}$. 
diameter [Fig. 3 (b)]. The grain size distribution broadens further with increased sintering time. The samples sintered in $\mathrm{H}_{2}$ show similar behaviour to those sintered in $75 \mathrm{~N}_{2}-25 \mathrm{H}_{2}$ (mol\%), but the grain size distribution is narrower and the maximum grain size smaller [Fig. 3 (c)].

Conventional TEM micrographs are shown in Fig. 4 (a) and (b). Micro-faceting is visible at the grain boundary of the sample sintered in $\mathrm{O}_{2}$ [Fig. 4 (a)]. Ferroelectric domains are also visible. Micro-faceting is also visible at the grain boundary of the sample sintered in $\mathrm{H}_{2}$ [Fig. 4 (b)]. In the sample sintered in $\mathrm{H}_{2}$, the ferroelectric domains are much reduced in size. The reduction in domain size indicates that the sample is changing from a normal first-order ferroelectric material to a relaxor material, ${ }^{18)}$ as observed in our previous work. ${ }^{15,16)}$
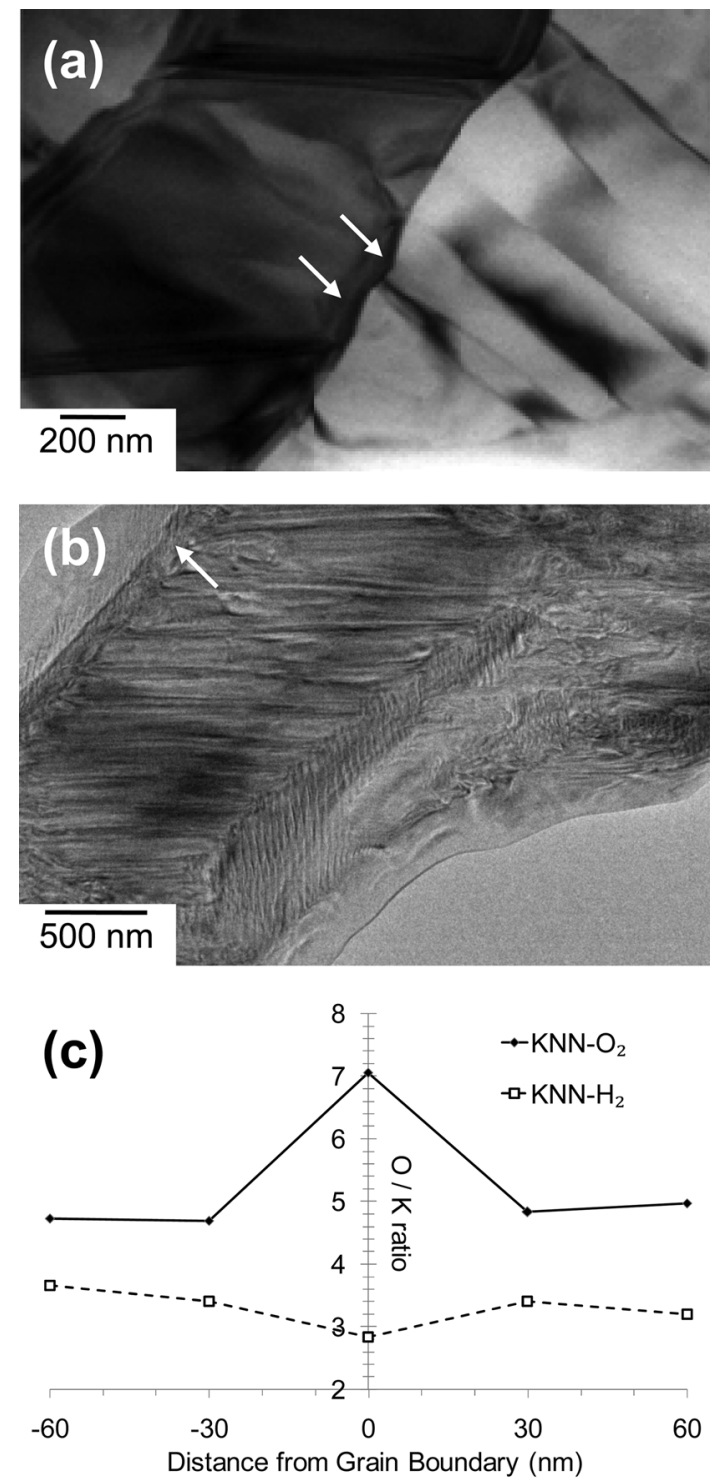

Fig. 4. TEM micrographs of $\left(\mathrm{K}_{0.5} \mathrm{Na}_{0 .}\right) \mathrm{NbO}_{3}$ ceramics sintered at $1040^{\circ} \mathrm{C}$ in (a) $\mathrm{O}_{2}$ and (b) $\mathrm{H}_{2}$ for $2 \mathrm{~h}$. White arrows show microfaceting. (c) TEM-EELS measurements of $\mathrm{O} / \mathrm{K}$ ratio across the grain boundaries of $\left(\mathrm{K}_{05} \mathrm{Na}_{05}\right) \mathrm{NbO}_{3}$ samples sintered in $\mathrm{O}_{2}$ and $\mathrm{H}_{2}$ at $1040^{\circ} \mathrm{C}$ for $2 \mathrm{~h}$.
TEM electron energy loss spectroscopy (TEM-EELS) results are shown in Fig. 4 (c). For the sample sintered in $\mathrm{O}_{2}$, four grain boundaries were observed and for the sample sintered in $\mathrm{H}_{2}$, five grain boundaries were observed. Each set of data represents representative results from one grain boundary. For the sample sintered in $\mathrm{O}_{2}$, the $\mathrm{O} / \mathrm{K}$ ratio increases considerably at the grain boundary, whereas for the sample sintered in $\mathrm{H}_{2}$ the $\mathrm{O} / \mathrm{K}$ ratio decreases slightly at the grain boundary. The $\mathrm{O} / \mathrm{K}$ ratios in the sample sintered in $\mathrm{H}_{2}$ are lower than those of the sample sintered in $\mathrm{O}_{2}$, both in the bulk of the grain and at the grain boundary.

XRD traces of the samples sintered for $10 \mathrm{~h}$ are shown in Fig. 5 (a). The patterns can all be indexed with JCPDS card no. 77-0038 for monoclinic $\left(\mathrm{K}_{065} \mathrm{Na}_{035}\right) \mathrm{NbO}_{3}$. No secondary

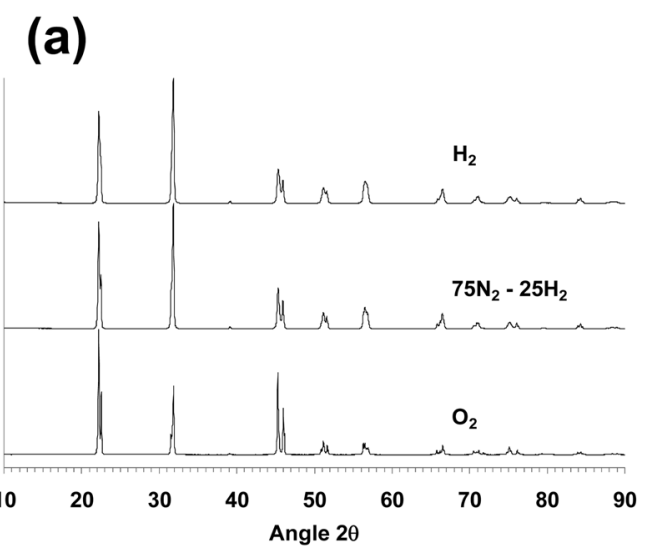

(b)

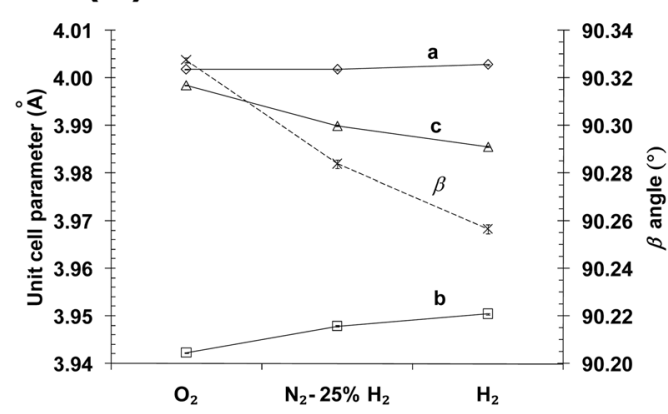

(c)

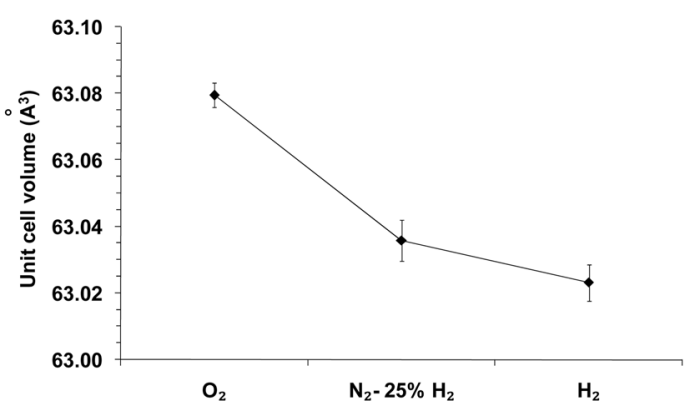

Fig. 5. (a) XRD traces, (b) unit cell parameters and (c) unit cell volume of $\left(\mathrm{K}_{05} \mathrm{Na}_{05}\right) \mathrm{NbO}_{3}$ ceramics sintered at $1040^{\circ} \mathrm{C}$ for $10 \mathrm{~h}$ in $\mathrm{O}_{2}, 75 \mathrm{~N}_{2}-25 \mathrm{H}_{2}(\mathrm{~mol} \%)$ and $\mathrm{H}_{2}$. 
phases are visible. Unit cell parameters of the samples are shown in Fig. 5 (b). The error bars show the estimated error of the refinement. The $a$ unit cell parameter remains almost constant with changing sintering atmosphere. The $b$ unit cell parameter increases as the sintering atmosphere becomes more reducing. The $c$ unit cell parameter and the angle $\beta$, both decrease as the sintering atmosphere becomes more reducing. The unit cell volume also decreases as the sintering atmosphere becomes more reducing [Fig. 5 (c)]. Again, the error bars show the estimated error.

\section{Discussion}

$\left(\mathrm{K}_{0.5} \mathrm{Na}_{0.5}\right) \mathrm{NbO}_{3}$ is well known to be a difficult ceramic to densify. ${ }^{9}$ ) To achieve high density $\left(\mathrm{K}_{0.5} \mathrm{Na}_{0.5}\right) \mathrm{NbO}_{3}$ ceramics (>95\% theoretical density) by conventional sintering techniques requires careful control of sintering conditions ${ }^{19)}$ or addition of sintering aids. ${ }^{20)}$ In the present work, densities $>95 \%$ theoretical density could be achieved by sintering in $75 \mathrm{~N}_{2}-25$ $\mathrm{H}_{2}$ (mol\%) and $\mathrm{H}_{2}$ even at the low sintering temperature of $1040^{\circ} \mathrm{C}$ (Fig. 1). This is higher than previous results for $\left(\mathrm{K}_{0.5} \mathrm{Na}_{0.5}\right) \mathrm{NbO}_{3}$ sintered in air at low temperature (e.g. a density of $86.9 \%$ theoretical density for $\left(\mathrm{K}_{0.5} \mathrm{Na}_{0.5}\right) \mathrm{NbO}_{3}$ sintered at $1030^{\circ} \mathrm{C}$ for $8 \mathrm{~h}^{8)}$ ) and is comparable to samples sintered at $1100^{\circ} \mathrm{C}$ (e.g. a density of $94.9 \%$ theoretical density after sintering at $1100^{\circ} \mathrm{C}$ for $2 \mathrm{~h}^{8)}$ ). Sintering in reducing atmospheres is expected to cause an increase in the concentration of oxygen vacancies, ${ }^{21,22)}$ which may assist densification by increasing the lattice diffusion rate of oxygen.

The SEM and TEM micrographs show that $\left(\mathrm{K}_{0.5} \mathrm{Na}_{0.5}\right) \mathrm{NbO}_{3}$ has faceted grain boundaries (Fig. 2 and Fig. 4), as has also been found in earlier works. ${ }^{8,14)}$ For faceted grain boundaries, grain growth takes place by the step growth mechanism, which is analogous to the growth of crystals by 2D-nucleation. ${ }^{23-27)}$ For 2D-nucleation controlled growth, the growth rate of a grain has an exponential dependence on the driving force for grain growth $\Delta \mathrm{G}^{2{ }^{26,28)}}$ Below a critical driving force $\Delta G_{C}$, grain growth is very slow but for driving forces greater than $\Delta \mathrm{G}_{\mathrm{C}}$ the grain growth rate increases rapidly. ${ }^{26)}$ For $\Delta \mathrm{G}>\Delta \mathrm{G}_{\mathrm{C}}$, kinetic roughening of the grain boundary takes place and the growth rate assumes a linear dependence on $\Delta \mathrm{G}^{25,29)}$ The driving force for grain growth $\Delta \mathrm{G}$ depends on the difference in size between the growing or shrinking grain and the mean grain size. ${ }^{30)}$ During sintering of a sample there will be a range of values of $\Delta \mathrm{G}$ which will initially be determined by the particle size distribution of the ceramic powder.

The critical driving force $\Delta \mathrm{G}_{\mathrm{C}}$ is given by ${ }^{28)}$ :

$$
\Delta G_{C}=\frac{\Omega \varepsilon^{2}}{3 h R T}
$$

where $\Omega=$ molar volume, $\varepsilon=$ step free energy of the nucleus, $h=$ step height of the nucleus, $R=$ the gas constant and $T=$ temperature. $\varepsilon$ is the excess energy associated with the edge of the $2 \mathrm{D}$ nucleus. The value of $\Delta \mathrm{G}_{\mathrm{C}}$ is very dependent on the step free energy $\varepsilon$. $\varepsilon$ in turn is affected by sintering temper- ature $^{17,31,32)}$ and atmosphere. ${ }^{14,33-35)}$ Sintering $\left(\mathrm{K}_{0.5} \mathrm{Na}_{0.5}\right) \mathrm{NbO}_{3}$ in reducing atmospheres is expected to cause an increase in oxygen vacancy concentration. ${ }^{21,22)}$ From the TEM-EELS results [Fig. 4 (c)], it can be seen that the $\mathrm{O} / \mathrm{K}$ ratio is lower in the $\left(\mathrm{K}_{0.5} \mathrm{Na}_{0.5}\right) \mathrm{NbO}_{3}$ sample sintered in $\mathrm{H}_{2}$ than in the sample sintered in $\mathrm{O}_{2}$. This indicates that the sample sintered in $\mathrm{H}_{2}$ has an increased oxygen vacancy concentration. The dip in the $\mathrm{O} / \mathrm{K}$ ratio at the grain boundary also indicates that the grain boundary core contains more oxygen vacancies than the grain interior. This is expected if oxygen is migrating from the grain interior to the boundary and then from the boundary to the external atmosphere. The changes in unit cell parameters and volume [Fig. 5 (b) and (c)] are also consistent with an increase in vacancy concentration, as explained in our previous works. ${ }^{15,16)}$

The grain growth behaviour of the $\left(\mathrm{K}_{0.5} \mathrm{Na}_{0.5}\right) \mathrm{NbO}_{3}$ samples can be explained by considering the effect of the sintering atmosphere on the vacancy concentration. An increase in vacancy concentration lowers the configurational entropy ${ }^{36}$ which in turn lowers $\varepsilon^{37-39)}$ When the samples are sintered in $\mathrm{O}_{2}$, the vacancy concentrations are relatively low and $\varepsilon$ is relatively high. This causes the value of $\Delta \mathrm{G}_{\mathrm{C}}$ to be high. Most of the grains have $\Delta \mathrm{G}<\Delta \mathrm{G}_{\mathrm{C}}$ and can only grow very slowly. A small number of grains have $\Delta \mathrm{G} \geq \Delta \mathrm{G}_{\mathrm{C}}$. These grains grow rapidly to form abnormal grains [Fig. 2(a) and Fig. 3 (a)]. As the sintering time increases, the abnormal grains continue to grow. In addition, some of the slowly growing matrix grains grow large enough to have $\Delta \mathrm{G} \geq \Delta \mathrm{G}_{\mathrm{C}}$. These grains then grow rapidly to form abnormal grains. Therefore both the size and number of abnormal grains increase with sintering time [Fig. 3 (a)].

When the sintering atmosphere changes to $75 \mathrm{~N}_{2}-25 \mathrm{H}_{2}$ (mol\%), the concentration of oxygen vacancies increases, as seen in the TEM-EELS and XRD results. This causes a decrease in $\varepsilon$ and $\Delta \mathrm{G}_{\mathrm{C}}$. The number of grains which have $\Delta \mathrm{G}>$ $\Delta \mathrm{G}_{\mathrm{C}}$ and which can grow rapidly increases. All of the matrix grains are consumed by the rapidly growing abnormal grains and even after $0.5 \mathrm{~h}$ of sintering, the microstructure consists of coarse grains [Fig. 3 (b)]. With increased sintering time, the abnormal grains grow further; however their growth rate is limited because of their impingement upon each other. For the samples sintered in $\mathrm{H}_{2}$ the oxygen vacancy concentration increases further, causing a further decrease in $\varepsilon$ and $\Delta \mathrm{G}_{\mathrm{C}}$. This causes a further increase in the number of grains which have $\Delta \mathrm{G}>\Delta \mathrm{G}_{\mathrm{C}}$. Because the number of rapidly growing grains increases, impingement occurs earlier than in the case of the samples sintered in $75 \mathrm{~N}_{2}-25 \mathrm{H}_{2}(\mathrm{~mol} \%)$ and this results in a reduction of average grain size after impingement of the abnormal grains [Fig. 2 (d) and Fig. 3 (c)].

Therefore, by sintering at $1040^{\circ} \mathrm{C}$ and controlling the sintering atmosphere, the microstructure of $\left(\mathrm{K}_{0.5} \mathrm{Na}_{0.5}\right) \mathrm{NbO}_{3}$ can be varied from a bimodal microstructure to a coarse grained microstructure. As grain size is known to affect piezoelectrical properties, ${ }^{40)}$ this provides a way of controlling the piezoelectric properties of $\left(\mathrm{K}_{0.5} \mathrm{Na}_{0.5}\right) \mathrm{NbO}_{3}$. In addition, the present work shows that samples can be sintered to 
high density in reducing atmospheres even at low temperatures.

\section{Conclusions}

$\left(\mathrm{K}_{0.5} \mathrm{Na}_{0.5}\right) \mathrm{NbO}_{3}$ ceramics have been sintered in atmospheres of $\mathrm{O}_{2}, 75 \mathrm{~N}_{2}-25 \mathrm{H}_{2}$ (mol\%) and $\mathrm{H}_{2}$ at $1040^{\circ} \mathrm{C}$ and their grain growth behaviour characterised. $\left(\mathrm{K}_{0.5} \mathrm{Na}_{0.5}\right) \mathrm{NbO}_{3}$ displayed abnormal grain growth and as the sintering atmosphere became more reducing, the number of abnormal grains tended to increase. The change in grain growth behaviour with decreasing oxygen partial pressure is caused by an increase in vacancy concentration in the samples. This lowers the step free energy $\varepsilon$ and critical driving force $\Delta G_{C}$ necessary for rapid grain growth, increasing the number of grains which can grow rapidly to form abnormal grains. By controlling the sintering atmosphere at low sintering temperature, the microstructure can thus be varied from bimodal to coarsegrained. In addition, samples could be sintered to high density in reducing atmospheres even at low sintering temperature.

\section{Acknowledgments}

This work was supported by the National Research Foundation of Korea (NRF Grant Nos. 2009-0094039 and 20100000739) funded by the Ministry of Education, Science and Technology, Korea. The authors would like to thank SeonYoung Lee for operating the SEM, Mi-Ja Woo for operating the XRD, Su-Min Shin for operating the JEOL 3010 TEM and Jenny Tellier (Jožef Stefan Institute, Slovenia) for carrying out the Rietveld refinement.

\section{REFERENCES}

1. B. Jaffe, W. R. Cook Jr, and H. Jaffe, "Chapter 8: Perovskite Niobates and Tantalates," p. 192-93 in Piezoelectric Ceramics, London: Academic Press; 1971.

2. E. Ringgaard and T. Wurlitzer, "Lead-Free Piezoceramics Based on Alkali Niobates," J. Eur. Ceram. Soc., 25 2701-6 (2005).

3. R. E. Jaeger and L. Egerton, "Hot Pressing of PotassiumSodium Niobates," J. Am. Ceram. Soc., 45 [5] 209-13 (1962).

4. Y. Guo, K. Kakimoto, and H. Ohsato, " $\left(\mathrm{Na}_{0.5} \mathrm{~K}_{0.5}\right) \mathrm{NbO}_{3}$ $\mathrm{LiTaO}_{3}$ Lead-Free Piezoelectric Ceramics," Mater Lett., 59 241-44 (2005).

5. R. Zuo, X. Fang, and C. Ye, "Phase Transitional Behavior and Piezoelectric Properties of Lead-Free $\left(\mathrm{Na}_{0.5} \mathrm{~K}_{0.5}\right) \mathrm{NbO}_{3}$ $\left(\mathrm{Bi}_{0.5} \mathrm{~K}_{0.5}\right) \mathrm{TiO}_{3}$ Ceramics," J. Am. Ceram. Soc., 90 [8] 2424-28 (2007).

6. Y. Saito, H. Takao, T. Tani, T. Nonoyama, K. Takatori, T. Homma, T. Nagaya, and M. Nakamura, "Lead-Free Piezoceramics," Nature, 432 84-7 (2004).

7. H. Takao, Y. Saito, Y. Aoki, and K. Horibuchi, "Microstructural Evolution of Crystalline-Oriented $\left(\mathrm{K}_{0.5} \mathrm{Na}_{0.5}\right) \mathrm{NbO}_{3}$ Piezoelectric Ceramics with a Sintering Aid of $\mathrm{CuO}$," J. Am. Ceram. Soc., 89 [6] 1951-6 (2006).

8. D. Jenko, A. Benčan, B. Malið, J. Holc, and M. Kosec, "Elec- tron Microscopy Studies of Potassium Sodium Niobate Ceramics," Microsc Microanal, 11 572-80 (2005).

9. H. Du, Z. Li, F. Tang, S. Qu, Z. Pei, and W. Zhou, "Preparation and Piezoelectric Properties of $\left(\mathrm{K}_{0.5} \mathrm{Na}_{0.5}\right) \mathrm{NbO}_{3}$ LeadFree Piezoelectric Ceramics with Pressure-Less Sintering," Mater. Sci. Eng. B., 131 83-7 (2006).

10. B. Malic, J. Bernard, A. Bencan, and M. Kosec, "Influence of Zirconia Addition on the Microstructure of $\mathrm{K}_{0.5} \mathrm{Na}_{0.5} \mathrm{NbO}_{3}$ Ceramics," J. Eur. Ceram. Soc., 28 1191-6 (2008).

11. Y. Zhen and J. F. Li, "Abnormal Grain Growth and New Core-Shell Structure in $(\mathrm{K}, \mathrm{Na}) \mathrm{NbO}_{3}$-Based Lead-Free Piezoelectric Ceramics," J. Am. Ceram. Soc., 90 [11] 3496502 (2007).

12. Y. M. Chiang, D. Birnie III, and W. D. Kingery, "Chapter 5: Microstructure,” p. 351-513, Physical Ceramics: Principles for Ceramic Science and Engineering New York, John Wiley \& Sons, 1997.

13. J. J. Choi, J. Ryu, and H. E. Kim, "Microstructural Evolution of Transparent PLZT Ceramics Sintered in Air and Oxygen Atmospheres," J. Am. Ceram. Soc., 84 [7] 1465-69 (2001).

14. J. G. Fisher and S. J. L. Kang, "Microstructural Changes in $\left(\mathrm{K}_{0.5} \mathrm{Na}_{0.5}\right) \mathrm{NbO}_{3}$ Ceramics Sintered in Various Atmospheres," J. Eur. Ceram. Soc., 29 2581-88 (2009).

15. J. G. Fisher, D. Rout, K. S. Moon, and S. J. L. Kang, "HighTemperature X-Ray Diffraction and Raman Spectroscopy Study of $\left(\mathrm{K}_{0.5} \mathrm{Na}_{0.5}\right) \mathrm{NbO}_{3}$ Ceramics Sintered in Oxidizing and Reducing Atmospheres," Mater. Chem. Phy., 120 [2-3] 26371 (2010).

16. J. G. Fisher, D. Rout, K. S. Moon, and S. J. L. Kang, "Structural Changes in Potassium Sodium Niobate Ceramics Sintered in Different Atmospheres," J. Alloys. Compounds., 479 467-72 (2009).

17. J. G. Fisher, M. S. Kim, H. Y. Lee, and S. J. L. Kang, "Effect of $\mathrm{Li}_{2} \mathrm{O}$ and $\mathrm{PbO}$ Additions on Abnormal Grain Growth in the $\mathrm{Pb}\left(\mathrm{Mg}_{1 / 3} \mathrm{Nb}_{2 / 3}\right) \mathrm{O}_{3}-35 \mathrm{~mol} \% \mathrm{PbTiO}_{3}$ System," J. Am. Ceram. Soc., 87 [5] 937-42 (2004).

18. W. Qu, X. Zhao, and X. Tan, "In-Situ Transmission Electron Microscopy Study of the Nanodomain Growth in a Sc-Doped Lead Magnesium Niobate Ceramic," Appl. Phys. Lett., 89 022904 1-3 (2006).

19. H. Birol, D. Damjanovic, and N. Setter, "Preparation and Characterization of $\left(\mathrm{K}_{0.5} \mathrm{Na}_{0.5}\right) \mathrm{NbO}_{3}$ Ceramics," J. Eur. Ceram. Soc., 26 861-66 (2006).

20. M. Matsubara, T. Yamaguchi, K. Kikuta, and S. Hirano, "Sinterability and Piezoelectric Properties of (K,Na) $\mathrm{NbO}_{3}$ Ceramics with Novel Sintering Aid," Jpn. J. Appl. Phys., 43 [10] 7159-63 (2004).

21. A. Shigemi and T. Wada, "Enthalpy of Formation of Various Phases and Formation Energy of Point Defects in PerovskiteType $\mathrm{NaNbO}_{3}$ by First-Principles Calculation," Jpn. J. Appl. Phys., 43 [9B] 6793-98 (2004).

22. A. Shigemi and T. Wada, "Evaluations of Phases and Vacancy Formation Energies in $\mathrm{KNbO}_{3}$ by First-Principles Calculation," Jpn. J. Appl. Phys., 44 [11] 8048-54 (2005).

23. H. Gleiter, "The Mechanism of Grain Boundary Migration," Acta. Metall., 17 565-73 (1969).

24. K. L. Merkle and L. J. Thompson, "Atomic-Scale Observation of Grain Boundary Motion,” Mater. Lett., 48 188-93 (2001).

25. S. B. Lee and Y. M. Kim, "Kinetic Roughening of a $\Sigma 5$ Tilt 
Grain Boundary in $\mathrm{SrTiO}_{3}$, , Acta. Mater., 57 5264-9 (2009).

26. J. P. Hirth and G. M. Pound, "Chapter D: Growth and Evaporation of Liquids and Dislocation-Free Crystals," p. 77-101, Condensation and Evaporation: Nucleation and Growth Kinetics Oxford: Pergamon Press; 1963.

27. H. Gleiter, "The Formation of Annealing Twins," Acta. Metall., 17 1421-28 (1969).

28. J. P. van der Eerden, Chapter 6: "Crystal Growth Mechanisms,” p. 311-475 in: D.T.J Hurle (Ed.), Handbook of Crystal Growth, Vol. 1, Fundamentals, Part A, Thermodynamics and Kinetics, Amsterdam: Elsevier Science Publishers; 1993.

29. S. D. Peteves and R. Abbaschian, "Growth Kinetics of SolidLiquid Ga Interfaces: Part II. Theoretical,” Metall. Trans. A., 22 1271-86 (1991).

30. D. Y. Yoon, C. W. Park, and J. B. Koo, "The Step Growth Hypothesis for Abnormal Grain Growth," pp. 3-21 in: H. I. Yoo, S. J. L. Kang (Eds.), Ceramic Interfaces 2 London: Institute of Materials; 2001.

31. H. J. Leamy and G. H. Gilmer, "The Equilibrium Properties of Crystal Surface Steps,” J. Cryst. Growth., 24/25 499-502 (1974).

32. H. van Beijeren, "Exactly Solvable Model for the Roughening Transition of a Crystal Surface," Phys. Rev. Lett., 38 [18] 993-96 (1977).

33. B. K. Lee, S. Y. Chung, and S. J. L. Kang, "Grain Boundary
Faceting and Abnormal Grain Growth in $\mathrm{BaTiO}_{3}$," Acta. Mater., 48 1575-80 (2000).

34. Y. I. Jung, S. Y. Choi, and S. J. L. Kang, "Effect of Oxygen Partial Pressure on Grain Boundary Structure and Grain Growth Behavior in $\mathrm{BaTiO}_{3}$," Acta. Mater., 54 2849-55 (2006).

35. S. Y. Chung, D. Y. Yoon, and S. J. L. Kang, "Effect of Donor Concentration and Oxygen Partial Pressure on Interface Morphology and Grain Growth Behaviour in $\mathrm{SrTiO}_{3}$," Acta. Mater., 50 3361-71 (2002).

36. Y. M. Chiang, D. Birnie III, and W. D. Kingery, "Chapter 2: Defects in Ceramics," pp. 101-184, Physical Ceramics: Principles for Ceramic Science and Engineering. New York: John Wiley \& Sons; 1997.

37. W. K. Burton, N. Cabrera, and F. C. Frank, "The Growth of Crystals and the Equilibrium Structure of their Surfaces," Philos. Trans. R. Soc. Lon. Ser. A., 243 299-358 (1951).

38. E. D. Williams and N. C. Bartelt, "Thermodynamics of Surface Morphology," Science, 251 393-400 (1991).

39. E. D. Williams, "Surface Steps and Surface Morphology: Understanding Macroscopic Phenomena from Atomic Observations," Surface Science, 299/300 502-24 (1994).

40. C. A. Randall, N. Kim, J. P. Kucera, W. Cao, and T. R. Shrout, "Intrinsic and Extrinsic Size Effects in Fine-Grained Morphotropic-Phase-Boundary Lead Zirconate Titanate Ceramics," J. Am. Ceram. Soc., 81 [3] 677-88 (1998). 